\title{
Promoção da saúde única: concepções e percepções sobre ambiente e saúde de professores de uma escola pública em Xerém
}

\author{
Greisieli Duarte Pereira \\ Doutoranda e Mestre em Ensino de Biociências e Saúde (IOC/Fiocruz)/ Laboratório de Avaliação Promoção da \\ Saúde Ambiental do Instituto Oswaldo Cruz/FIOCRUZ e pesquisadora do grupo de pesquisa em Saúde e \\ Educação Ambiental com ênfase nas relações parasitárias (Saúde EAC/IOC/Fiocruz) \\ $\triangle$ greisiellid@uerj.br

\section{Clélia Christina Mello-Silva} \\ Pós- doutora em Educação (PPGEduc/UFRRJ)/ pesquisadora do Laboratório de Avaliação e Promoção da \\ Saúde Ambiental do Instituto Oswaldo Cruz/FIOCRUZ e líder do grupo de pesquisa em Saúde e Educação \\ Ambiental com ênfase nas relações parasitárias (Saúde EAC/IOC/Fiocruz) \\ $\triangle$ clelia@ioc.fiocruz.br
}

\section{Resumo:}

A escola é compreendida como um núcleo educativo, onde além do ensino formal, outras perspectivas como a saúde, fomentam reflexões críticas sobre a realidade e contribuem para a construção de um pensamento complexo. Nesse contexto, os professores são os mentores dos alunos no espaço escolar, pois conduzem os discentes a construção do conhecimento e de sua cidadania. Dada a relevância do binômio "saúde e ambiente" este estudo tem por objetivo apresentar as concepções e percepções de professores de uma escola pública, sobre saúde e ambiente, para a elaboração de propostas interventivas visando a promoção da saúde única (One Health). Para o conhecimento das concepções e percepções sobre saúde e ambiente dos docentes foi elaborado como instrumento de coleta de dados um questionário semi-estruturado. As concepções e percepções de cada participante sobre os temas foram analisadas por meio da técnica análise de Conteúdo de Bardin. As concepções e percepções dos docentes quanto a saúde e ambiente estão pautadas em uma visão paradigmática sustentadas por um pensamento simplista, observado em suas falas e práticas. Essas concepções comandam o discurso e a práxis do professor, muitas vezes limitando suas possibilidades e criatividade, negligenciando o potencial de suas ações e intenções.

Palavras-chave: Saúde única, Ambiente, Processo de ensino-aprendizagem, Promoção da Saúde.

\section{One Health Promotion: conceptions and perceptions of the environment and health of teachers in a public school in Xerém}

\begin{abstract}
:
The school is understood as an educational nucleous, where besides formal education, other perspectives such as health foster critical reflections on reality and contribute to the construction of complex thinking. In this context, teachers are the mentors of the students in the school space, since they lead the students to the construction of knowledge and their citizenship. Given the relevance of the binomial 'health and environment', this study aims to present the conceptions and perceptions of teachers of a public school, about health and environment, for the elaboration of intervening proposals aiming at the promotion of unique health (One Health). For the knowledge of the conceptions and perceptions about health and environment of teachers, a semi-structured questionnaire was elaborated as a data collection tool. The conceptions and perceptions of each
\end{abstract}


participant about the themes were analyzed through the Bardin Content analysis technique. Teachers' conceptions and perceptions about health and environment are based on a paradigmatic vision supported by a simplistic thought, observed in their speeches and practices. These conceptions command the teacher's discourse and practice, often limiting their possibilities and creativity, neglecting the potential of their actions and intentions.

Keywords: One Health, environment, teaching-learning, Health Promotion.

\title{
Promoción de la salud única: concepciones y percepciones del medio ambiente y la salud de los profesores de una escuela pública en Xerém
}

\begin{abstract}
Resumen:
La escuela se entiende como un núcleo educativo, donde además de la educación formal, la escuela se relaciona con la salud. La cual fomenta reflexiones críticas sobre la realidad y contribuyen a la construcción de un pensamiento complejo. En este contexto, los profesores son los mentores de los estudiantes en el espacio escolar, porque conducen a los estudiantes a la construcción del conocimiento y de su ciudadanía. Dada la relevancia del binomio "salud y medio ambiente", este estudio pretende presentar las percepciones y concepciones de los profesores de una escuela pública, sobre la salud y el medio ambiente, para la elaboración de propuestas de intervención destinadas a la promoción de la Salud Única (One Health) Para conocer las concepciones y percepciones sobre la salud y el medio ambiente de los profesores, se elaboró como instrumento de recopilación de datos un cuestionario semiestructurado compuesto por preguntas abiertas y semiabiertas. Las concepciones y percepciones de cada participante sobre los temas se analizaron mediante la técnica de análisis de contenido de Bardin. Las concepciones y percepciones de los profesores sobre la salud y el medio ambiente se basan en una visión paradigmática apoyada en un pensamiento simplista, observado en sus discursos y prácticas. Estas concepciones dominan el discurso y la práctica del profesor, limitando a menudo sus posibilidades y creatividad, descuidando el potencial de sus acciones e intenciones. Palabras clave: Salud Única, Medio Ambiente, Enseñanza-aprendizaje, Promoción de la Salud.
\end{abstract}

\section{INTRODUÇÃO}

A saúde, intrinsecamente, sempre esteve associada à organização sociopolítica, econômica e cultural da população. No entanto, as civilizações antigas desconheciam estas relações e atribuíam a ela um caráter divino de acordo com suas crenças e práticas religiosas (SCLIAR, 2007). Em meados do século XX, dentro do período histórico de reestruturação sociopolítica Pós-Segunda Guerra Mundial, com a criação da Organização das Nações Unidas (ONU) e da Organização Mundial de Saúde (OMS) a saúde passa a ser compreendida de forma mais abrangente. Em 22 de Julho de 1946, a OMS apresenta em sua constituição a seguinte afirmativa "A saúde é um estado de completo bem-estar físico, mental e social, e não consiste apenas na ausência de doença ou de enfermidade".

Neste contexto, o bem-estar humano, individual e coletivo ultrapassa os limites biológicos e está associado às condições sociais, culturais e ambientais. Dessa forma, tanto a saúde como sua promoção estão relacionadas às ações do ser humano frente ao ambiente em 
que vive. Nesse sentido, é preciso sensibilizar a sociedade, quanto a reciprocidade do cuidado humano-humano e humano-ambiental (BRASIL, 2002; MELLO-SILVA e GUIMARÃES, 2018). O ser humano, como qualquer outro ser vivo, é parte integrante do ambiente e dele depende para sobreviver (MELLO-SILVA-SILVA, 2017). Dessa forma, é seu dever cuidar do ambiente em que vive e compartilha.

O cuidado se manifesta com amorosidade e empatia. Esta atitude afetuosa constitui o sentimento de pertencimento, fato que proporciona a construção de uma relação afetiva com a territorialidade (MARCEZWSKI, 2006). O sentimento de pertencimento impulsiona o processo de cuidado com o ambiente, promovendo a saúde e não a destruição do mesmo. Desse modo, a crise ambiental é uma crise civilizatória (GUIMARÃES, 2012).

Diante do contexto atual de esmagadora degradação ambiental, o ser humano parece estar cordialmente desgarrado do seu próprio ecossistema, desintegrando-se da natureza, assumindo o papel de predador em detrimento do cuidado (BOFF, 2017). Isto interfere diretamente na saúde planetária, acometendo a qualidade de vida de todos os seres humanos e não-humanos.

Nos primórdios do século XXI, foi introduzido um novo olhar sobre a saúde fundamentado não mais apenas sobre a égide da saúde humana. Nesse sentido, cunhou-se o termo One Health ou Saúde Única. A saúde única é uma iniciativa integrativa de visão transdisciplinar, constituindo uma estratégia que considera e articula a saúde humana, a saúde animal e a saúde ambiental (GIBBS, 2014). Recentemente, esta ideologia tem sido associada a questão da qualidade de vida planetária de forma abrangente. A ampliação do termo nos fez pensar que a saúde planetária deve ser a relevância, ou seja, uma única saúde para um único planeta (MELLO-SILVA e GUIMARÃES, 2018).

Diante do reconhecimento da interdependência entre ambiente-saúde, bem como da integração dos seres vivos junto ao ecossistema planetário, a visão de bem-estar e saúde foi ressignificada. No entanto, parece existir uma incoerência entre a teoria e a realidade atual, vide o evidente sucateamento do ambiente, somado as consequentes implicações e agravos à saúde provenientes da relação desequilibrada entre homem-ambiente.

De acordo com Guimarães (2012), a sociedade moderna apresenta uma visão reducionista da realidade, baseado na filosofia do pensamento simplista, que tudo segmenta. 
Inconscientemente esta ideologia comanda a conduta, o fazer, a construção do olhar, do pensamento e das concepções dos indivíduos influenciando o modo de viver dos mesmos. Desse modo, os paradigmas que permeiam a sociedade moderna influenciam as ações dos sujeitos sociais.

O pensamento simplista se coloca como impedimento ao holismo, visão fundamental para vencer o paradigma da disjunção e superar a crise socioambiental. Desse modo, é preciso abrir o caminho para o pensamento complexo, retirando desta via todas as barreiras reducionistas que bloqueiam a formação de um sujeito social e ecologicamente crítico em suas concepções, pois estas implicam diretamente na conduta, práxis e modo de vida do ser humano (MELLO-SILVA e GUIMARÃES).

Para isso, são necessárias ações educativas transformadoras que permitam esta mudança de paradigma. Acredita-se que a Educação Ambiental Crítica (EAC) possibilita esta conversão. Esta crença se estabelece porque a EAC apresenta na sua episteme, os seguintes pressupostos: o pensamento complexo da realidade (MORIN, 2000), a dialética de Karl Marx (1981) e a pedagogia libertadora de Paulo Freire (1996). Além disso, a EAC aborda as relações dos seres humanos frente ao cuidado com o ambiente e com os demais seres vivos deste planeta (MELLO-SILVA e GUIMARÃES, 2018).

A escola é compreendida como um núcleo educativo, onde além do ensino formal, outras perspectivas educativas podem fomentar reflexões críticas sobre a realidade e contribuir para a construção de um pensamento complexo (BOAVENTURA, 2009). Desse modo, frente a um mundo em constante globalização é preciso investir em ações educativas promotoras de saúde, dentro da perspectiva planetária, considerando os fatores socioambientais. Estas ações devem ser populares e participativas para construção e reconstrução do conhecimento promovendo autonomia (prática libertadora), cidadania, solidariedade e justiça social (BRASIL, 2007; FREIRE, 1989).

Nesse contexto, os professores são os grandes mentores dos alunos no espaço escolar, pois conduzem os discentes a construção do conhecimento e de sua cidadania (CARDOSO, REIS, IERVOLINO, 2008). Dada à relevância do binômio "saúde e ambiente", interessa-nos conhecer as concepções e percepções dos docentes sobre esta temática, uma vez que poderão contribuir com a construção do conhecimento sobre saúde única ou una, favorecendo a 
autonomia e o empoderamento da comunidade escolar. Neste aspecto, contribuem com a formação da cidadania e com o desenvolvimento de ações democráticas, sustentáveis e saudáveis dentro da realidade local interna e externa ao seu território.

Este estudo tem por objetivo apresentar as percepções e concepções de professores de uma escola pública, sobre saúde e ambiente, para a elaboração de propostas interventivas na comunidade escolar, visando a promoção da saúde única.

\section{METODOLOGIA}

Este estudo foi desenvolvido em uma Escola Pública localizada em Xerém, quarto distrito do município de Duque de Caxias do Estado do Rio de Janeiro . 0 projeto ${ }^{1}$ foi submetido e aprovado pelo Comitê de Ética em Pesquisa do Instituto Oswaldo Cruz/ Fiocruz com o número 3.288.740. Os sujeitos da pesquisa foram os docentes da respectiva escola. Os professores participantes assinaram o Termo de Consentimento Livre e Esclarecido (TCLE).

Esta pesquisa está baseada na vertente metodológica da pesquisa-ação participante. De acordo com Tozoni-Reis (2007), a pesquisa ação-participativa confere uma metodologia aplicada aos processos de construção dos saberes em educação, incluindo o agir educativo em educação ambiental. Nesta modalidade, o sujeito não é passivo, mas ativo. Dessa forma, os indivíduos não são considerados simplesmente como objeto de estudo, uma vez que, como atores sociais, atuam diretamente na produção do conhecimento por meio de um processo de avaliação e reflexão, cujo objetivo transcende a "mudança de comportamento", mas a ampliação de concepções que visam a formação de sujeitos socialmente críticos, que democraticamente participam do processo de tomada decisão para as demandas do território.

Para o conhecimento das concepções e percepções sobre saúde e ambiente dos docentes, foi elaborado como instrumento de coleta de dados um questionário

\footnotetext{
${ }^{1}$ Este estudo faz parte da Dissertação" Promoção da Saúde: fatores ambientais que intervêm no processo de ensino-aprendizagem em uma escola pública do distrito de Xerém, município de Duque de Caxias, RJ" do Programa de Pós- Graduação em Ensino em Biociências e Saúde, IOC/Fiocruz, apresentada ao Instituto Oswaldo Cruz para obtenção do título Mestre em Ensino em Biociências e Saúde, sob orientação da Dra. Clélia ChristinaMello-Silva.
} 
semiestruturado. Este instrumento é anônimo, constituído por oito questões que abordam as temáticas saúde, ambiente, saúde única, fatores de riscos ambientais, doenças e atividades educativas desempenhadas pelos professores voltadas à saúde. Os questionários foram entregues aos docentes para que tivessem a opção de respondê-lo no momento que julgassem oportuno, dentro do prazo estabelecido para o recolhimento do mesmo.

As concepções e percepções de cada participante sobre saúde e ambiente estão descritas no questionário e foram analisadas qualitativamente, organizadas em categorias que refletem a frequência de respostas com sentidos semelhantes conferidos a temática proposta por meio da técnica Análise de Conteúdo de Bardin (2010). Desse modo, a análise foi construída em três fases: 1. pré-análise, 2. exploração do material e 3. interpretação dos resultados, considerando a frequência de apresentação de cada características ou elementos da mensagem. A análise por categoria consistiu em agrupar segmentos similares do texto e classificá-los, a partir das significações atribuídas pelo codificador. Neste estudo, a categorização dos elementos linguísticos foi realizada a partir dos achados do questionário.

\section{RESULTADOS}

Responderam ao questionário 31 professores, representando 46,9\% do corpo docente da instituição. Estes serão representados pela letra P seguida de número. Os professores pertencem às seguintes áreas de conhecimento: Artes e Educação física (3); Ciências Naturais (Física, Biologia e Química) (5); Filosofia e Sociologia (6); Geografia e História (6); Linguagens (português e Inglês) (8); Matemática (4), sendo 14 do gênero feminino (F) e 16 do gênero masculino (M),com idades variando entre 25 a 59 anos. Os perfis dos sujeitos da pesquisa estão apresentados nas tabelas 1 e 2.

As concepções e percepções foram analisadas, categorizadas e estão apresentadas nas tabelas (3 a 9 ). 
Tabela 1- Faixa etária dos docentes pesquisados de uma escola pública do distrito de Xerém, Duque de Caxias/RJ

\begin{tabular}{cll}
\hline Idade & No Professores & \% Professores \\
\hline $20-30$ & 3 & $9,6 \%$ \\
$31-40$ & 8 & $25,8 \%$ \\
$41-50$ & 7 & $22,5 \%$ \\
$51-60$ & 12 & $38,7 \%$ \\
NR* & 1 & $3,2 \%$ \\
\hline Total & 31 & $100 \%$
\end{tabular}

Fonte:Própria Autora.

Tabela 2 - Tempo total de Magistério e Tempo de Magistério na escola

\begin{tabular}{|c|c|c|c|c|c|c|c|c|c|}
\hline \multirow{2}{*}{$\begin{array}{l}\text { Professores } \\
\text { por área }\end{array}$} & \multicolumn{4}{|c|}{ Tempo de magistério total (\%) } & \multicolumn{5}{|c|}{ Tempo de Magistério na escola (anos) (\%) } \\
\hline & $1-10$ & $11-20$ & $21-30$ & $31-40$ & $0-1$ & $2-10$ & $11-20$ & + de 20 & $\mathrm{NR}^{*}$ \\
\hline $\begin{array}{l}\text { Artes e } \\
\text { Educação } \\
\text { Física }\end{array}$ & $11,1 \%$ & $22,2 \%$ & $0 \%$ & $0 \%$ & $33,3 \%$ & $5,5 \%$ & $16,6 \%$ & $0 \%$ & $0 \%$ \\
\hline $\begin{array}{l}\text { Ciências } \\
\text { (Física, } \\
\text { Biologia e } \\
\text { Química) }\end{array}$ & $11,1 \%$ & $33,3 \%$ & $0 \%$ & $25 \%$ & $0 \%$ & $16,6 \%$ & $16,6 \%$ & $33,3 \%$ & $0 \%$ \\
\hline $\begin{array}{l}\text { Filosofia e } \\
\text { Sociologia }\end{array}$ & $33,3 \%$ & $22,2 \%$ & $11,1 \%$ & $0 \%$ & $66,6 \%$ & $16,6 \%$ & $16,6 \%$ & $0 \%$ & $0 \%$ \\
\hline $\begin{array}{l}\text { Geografia e } \\
\text { História }\end{array}$ & $44,4 \%$ & $11,1 \%$ & $33,3 \%$ & $0 \%$ & $0 \%$ & $38,8 \%$ & $0 \%$ & $0 \%$ & $0 \%$ \\
\hline $\begin{array}{l}\text { Linguagens } \\
\text { (Português e } \\
\text { Inglês) }\end{array}$ & $0 \%$ & $22,2 \%$ & $55,5 \%$ & $25 \%$ & $0 \%$ & $22,2 \%$ & $50 \%$ & $33,3 \%$ & $0 \%$ \\
\hline Matemática & $0 \%$ & $11,1 \%$ & $33,3 \%$ & $50 \%$ & $0 \%$ & $11,1 \%$ & $0 \%$ & $33,3 \%$ & $3,3 \%$ \\
\hline
\end{tabular}

Fonte:Própria Autora. 
Tabela 3 - Frequência de respostas por categoria sobre a concepção de saúde

\begin{tabular}{lc}
\hline Respostas por categoria & $\begin{array}{c}\text { Número (Frequência) de resposta por } \\
\text { categoria }\end{array}$ \\
\hline Bem-estar físico, mental e social. & $23(74,1 \%)$ \\
Ausência de doença. & $5(16,1 \%)$ \\
Alimentação. & $2(6,4 \%)$ \\
Qualidade de Vida. & $3(9,6 \%)$ \\
\hline
\end{tabular}

Fonte: Própria Autora

As concepções dos professores foram agrupadas em quatro categorias que apresentam traços referentes aos diferentes paradigmas que surgiram ao longo do percurso histórico conceitual de saúde.

Tabela 4- Frequência de respostas por categoria sobre a concepção de ambiente

\begin{tabular}{cl}
\hline Respostas por categoria & $\begin{array}{l}\text { Número (Frequência) de resposta por } \\
\text { categoria }\end{array}$ \\
\hline Naturalista & $4(12,9 \%)$ \\
Antropocêntrica & $25(80,6 \%)$ \\
Globalizante & $2(6,4 \%)$ \\
\hline
\end{tabular}

Fonte: Própria Autora.

As concepções foram agrupadas em 3 categorias, de acordo com os modelos definidos por Reigota (1991) apud Bezerra e Gonçalves (2007) que definiu três tendências distintas que permeiam as concepções sobre ambiente, são elas: Naturalista, Antropocêntrica e Globalizante. 
Tabela 5 - Frequência de respostas por categoria sobre o conceito de One Health de ou Saúde única.

\begin{tabular}{lc}
\hline Respostas por categoria & Número (Frequência) de resposta por categoria \\
\hline Inter-relação de fatores & $1(3,2 \%)$ \\
Saúde Relacionada ao Ambiente. & $3(9,6 \%)$ \\
Saúde do homem e dos animais em & $1(3,2 \%)$ \\
Saúde humana & $1(3,2 \%)$ \\
Sistema único de Saúde & $1(3,2 \%)$ \\
\hline
\end{tabular}

Fonte: Própria Autora.

Ao serem questionados sobre o conhecimento do termo "One Health" ou "Saúde única", $64,74 \%$ dos professores responderam que não conheciam a terminologia. Cerca de 6,1\% da amostra afirmou conhecer o conceito, apresentando inferências sobre o tema.

Tabela 6 - Frequência de respostas por categoria sobre como o ambiente influencia no aparecimento de doenças.

Respostas por categoria

Fatores Psicossociais

Fatores físicos: Ruído, temperatura e iluminação

Poluição

Higiene.

Ambiente Insalubre

Clima
Frequência) de resposta por categoria

$9(29,0 \%)$

$7(22,5 \%)$

$6(19,3 \%)$

$4(12,9 \%)$

$2(6,4 \%)$

Fonte: Própria Autora. 
Observamos que os fatores ambientais adoecedores estão relacionados ao ambiente social, físico e natural. A categoria Fatores Psicossociais agrupa noções que abordam o ambiente social, como citado pelos seguintes professores: "[..] Ambiente desfavorável, bullying, ansiedade de cunho nervoso. Estresse" (P11), "Ambiente de pressão, estresse influencia no aparecimento de doenças físicas e mentais.” (P13), "Doenças mentais, físicas e psicológicas. Quando o sujeito trabalha sobre estresse" (P14); "Conviver com pessoas com carga negativa” (P8), “[..]Tento ensinar em um ambiente que não ajuda acabo me desgastando além da conta" (P27). Nota-se que a ambiência permeada pelas relações, para este grupo é um fator determinante para saúde e com alto potencial de adoecimento. Neste caso, o ambiente escolar e mais especificamente a sala de aula, local das relações e do desenvolvimento do processo de ensino-aprendizagem. A esfera psicossocial é significativa para os sujeitos e representa, para maioria dos participantes, o ambiente das relações professor-aluno e é determinante do processo de saúde-doença para este grupo. Por outro lado, este achado também reafirma a perspectiva reduzida de ambiente como visto na questão anterior. 0 ambiente psicossocial está diretamente associado à saúde humana e a qualidade de vida este ambiente se configura como determinante e indicador de saúde. Nesse contexto, os participantes atribuem as relações comunicativas estabelecidas neste ambiente como manifestação de agravos à saúde do indivíduo.

Tabela 7 - Frequência de respostas por categoria apresentando o levantamento de fatores de riscos, vetores ou veículos e doenças ou desconfortos adquiridos por professores ministrando aula na escola estudada.

\begin{tabular}{|c|c|c|c|c|c|}
\hline $\begin{array}{l}\text { Doença ou } \\
\text { desconforto }\end{array}$ & $\begin{array}{l}\text { Frequência } \\
\text { de resposta }\end{array}$ & $\begin{array}{l}\text { Vetor } \\
\text { veículo }\end{array}$ & $\begin{array}{l}\text { Frequência } \\
\text { de resposta }\end{array}$ & Fatores de Riscos & $\begin{array}{l}\text { Frequênciade } \\
\text { resposta }\end{array}$ \\
\hline Em Branco. & $17(54,8 \%)$ & Em Branco. & $23(74,1 \%)$ & $\begin{array}{l}\text { Temperatura } \\
\text { (Calor). }\end{array}$ & $4(9,6 \%)$ \\
\hline Nenhum & $3(9,6 \%)$ & Aluno. & $2(6,4 \%)$ & Ruído. & $3(9,6 \%)$ \\
\hline Rouquidão. & $2(6,4 \%)$ & Ambiente. & $3(6,4 \%)$ & $\begin{array}{l}\text { Trastorno } \\
\text { psicológico }\end{array}$ & $2(6,4 \%)$ \\
\hline
\end{tabular}




\begin{tabular}{|c|c|c|c|c|c|}
\hline $\begin{array}{l}\text { Transtorno } \\
\text { psicológico }\end{array}$ & $5(3,2 \%)$ & Psique & $1(3,2 \%)$ & $\begin{array}{l}\text { Condições } \\
\text { trabalho }\end{array}$ & $3(3,2 \%)$ \\
\hline Fadiga & $1(3,2 \%)$ & & & $\begin{array}{l}\text { Doenças } \\
\text { cardiovasculares }\end{array}$ & $2(3,2 \%)$ \\
\hline $\begin{array}{l}\text { Doenças } \\
\text { infecciosa }\end{array}$ & $2(3,2 \%)$ & & & & \\
\hline
\end{tabular}

Fonte: Própria Autora.

Os principais desconfortos citados pelos participantes foram os distúrbios vocais e os transtornos psicológicos. Ambas as categorias representam agravos comuns a profissão docente.

Tabela 8- Frequência de respostas sobre percepção dos fatores ambientais que influenciam positiva ou negativamente o processo de ensinoaprendizagem no ambiente escolar.

\begin{tabular}{|c|c|c|c|}
\hline $\begin{array}{l}\text { Respostas por } \\
\text { categoria } \\
\text { Fatores Positivos }\end{array}$ & $\begin{array}{c}\text { Número } \\
\text { (Frequência) de } \\
\text { resposta por } \\
\text { categoria }\end{array}$ & $\begin{array}{l}\text { Respostas por } \\
\text { categoria } \\
\text { Fatores negativos }\end{array}$ & $\begin{array}{c}\text { Número } \\
\text { (Frequência) de } \\
\text { resposta por } \\
\text { categoria }\end{array}$ \\
\hline $\begin{array}{l}\text { Não apresentou os } \\
\text { fatores positivos }\end{array}$ & $14(45,1 \%)$ & Calor/Climatização & $10(32,2 \%)$ \\
\hline Higiene e limpeza & $4(12,9 \%)$ & Ruído & $9(29,03 \%)$ \\
\hline $\begin{array}{l}\text { Tranquilidade, } \\
\text { segurança }\end{array}$ & $4(12,9 \%)$ & Superlotação das salas & $7(22,5 \%)$ \\
\hline Em branco & $3(9,6 \%)$ & $\begin{array}{l}\text { Não apresentou os fatores } \\
\text { negativos }\end{array}$ & $5(16,1 \%)$ \\
\hline Espaço físico & $3(9,6 \%)$ & & \\
\hline
\end{tabular}




$\begin{array}{lclc}\text { Ambiente arborizado } & 4(9,6 \%) & \text { Em Branco } & 3(9,6 \%) \\ \text { Alimentação } & 2(6,4 \%) & \begin{array}{l}\text { Alunos (Falta de interesse e } \\ \text { indisciplina) }\end{array} & 3(9,6 \%) \\ \text { Ambiente ao entorno } & 5(16,12 \%) & \text { Relações interpessoais } & 1(3,2 \%) \\ \begin{array}{l}\text { Relação professor- } \\ \text { aluno }\end{array} & 1(3,2 \%) & & \end{array}$

Fonte: Própria Autora.

No tocante a percepção dos fatores ambientais, $45 \%$ dos docentes não apresentaram fatores ambientais positivos sobre o ambiente escolar. Os demais destacaram fatores como: higiene, espaço físico e a tranquilidade da região onde a escola está inserida.

Tabela 9 - Professores por área de conhecimento: atividades educativas, ausências e agravos à saúde associado ao exercício da profissão.

\begin{tabular}{|c|c|c|c|c|c|c|}
\hline $\begin{array}{l}\text { Professores por } \\
\text { área de } \\
\text { conhecimento }\end{array}$ & $\begin{array}{l}\text { Artes e } \\
\text { Educação } \\
\text { Física }\end{array}$ & $\begin{array}{l}\text { Ciências } \\
\text { Naturais } \\
\text { (física, } \\
\text { biologia e } \\
\text { Química) }\end{array}$ & $\begin{array}{l}\text { Filosofia e } \\
\text { Sociologia }\end{array}$ & $\begin{array}{l}\text { Geografia e } \\
\text { História }\end{array}$ & $\begin{array}{l}\text { Linguagens } \\
\text { (português e } \\
\text { Inglês) }\end{array}$ & Matemática \\
\hline $\begin{array}{l}\text { Ministrou aula } \\
\text { com o tema } \\
\text { saúde e/ou } \\
\text { ambiente }\end{array}$ & $28,5 \%$ & $28,57 \%$ & $0 \%$ & $42,8 \%$ & $0 \%$ & $0 \%$ \\
\hline $\begin{array}{l}\text { Precisou se } \\
\text { ausentar por } \\
\text { problema de } \\
\text { saúde }\end{array}$ & $14,2 \%$ & $19 \%$ & $9,5 \%$ & $19 \%$ & $28,5 \%$ & $9,5 \%$ \\
\hline $\begin{array}{l}\text { Possui doença ou } \\
\text { desconforto } \\
\text { associado à sua } \\
\text { profissão }\end{array}$ & $9 \%$ & $18,1 \%$ & $18,1 \%$ & $18,18 \%$ & $36,3 \%$ & $0 \%$ \\
\hline
\end{tabular}

Fonte: Própria Autora. 
Dentre os agravos à saúde relacionados às ausências, ressaltamos os de maior relevância como a rouquidão, estresse, depressão, problemas respiratórios e osteomusculares. Quanto ao desenvolvimento de doenças ou desconforto relacionados ao exercício da sua profissão na referida instituição, foram relatados com maior relevância o estresse, os distúrbios da voz e problemas osteomusculares.

\section{DISCUSSÃO}

De acordo com o perfil dos sujeitos da pesquisa, a maioria 38,7\% dos docentes participantes, está inserida na faixa etária próxima da aposentadoria. Os mesmos possuem mais de 20 anos de magistério. Este dado reflete o perfil dos professores da Educação básica no Brasil citado por Souza (2013). O autor afirma que estes docentes são profissionais experientes que vem atuando na educação por um longo período apresentando uma faixa etária mais idosa. 0 autor acredita que este fato está relacionado à política de aposentadoria, implicando assim, na permanência do docente em atividade por um tempo além do necessário. Dessa forma, estamos diante de uma classe trabalhadora que, à medida que envelhece também permanece na profissão. Mesmo com a renovação do corpo docente institucional, a insistência na ativa implica no desgaste físico e psicológico destes profissionais.

As concepções e percepções apresentadas pelos docentes refletem um pensamento simplista e hegemônico alinhado a uma visão paradigmática que permeia a sociedade contemporânea. Com relação à definição de saúde, 74,15\% dos participantes apresentaram concepções de acordo com o conceito definido pela OMS em 1946, considerando a saúde como bem-estar. Este dado corrobora com o estudo dos autores Cardoso, Reis, Iervolino (2008) onde identificaram que $95 \%$ da amostra compreende saúde como bem-estar físico, mental e social.

É possível observar que há uma tendência à reprodução de um conceito para definir saúde. Desse modo, consideramos que este fato configura um paradigma. De acordo com Morin (1997) paradigmas são conceitos pré-estabelecidos concordados sem qualquer análise crítica que inconscientemente comandam o discurso e ações dos indivíduos. Desse modo, a reprodução do paradigma de saúde, não representa a reflexão destes docentes sobre a mesma. 
As categorias ausência de doença e alimentação, representam um pensamento simplista, considerando a saúde de forma fragmentada. Estas características coadunam com modelo biomédico de saúde (CZERESNIA e FREITAS, 2009). Rezende (2016) ao estudar a concepção de professores sobre saúde, também identificou a representação da mesma como ausência de doença.

Ao emitirmos o vocábulo saúde, automaticamente evocamos uma representação mental do seu sentido, cuja a referência está nas vivências e no conhecimento de mundo experimentado. Semanticamente, poderíamos construir um acervo peculiar de palavras e expressões relacionadas a este signo que, no entanto, só fariam sentido quando relacionados ao contexto de vida de cada indivíduo. Neste estudo, percebemos que as concepções de saúde dos professores coadunam com diferentes modelos de saúde.

Quanto ao conceito de ambiente, em nosso estudo as concepções foram categorizadas seguindo o modelo de Reigota (1991) apud Bezerra e Gonçalves (2007) como: Categoria Naturalista, que refere-se a natureza apenas como ambiente ecológico natural e restrito; Categoria Globalizante, que estabelece a inter-relação entre ambiente e sociedade e Categoria Antropocêntrica, onde o ser humano tem caráter dominante sendo representado como centro de todas as coisas (BEZERRA e GONÇALVES, 2007). Após analisarmos as noções agrupadas em cada categoria, observamos que para boa parte deste grupo, o ambiente é traduzido como um espaço social de relações, onde sua atmosfera psicossocial é determinante para saúde.

O ambiente retratado na categoria antropocêntrica, que agrupa cerca de 83,8 \% das concepções, é o espaço de convívio do ser humano. Bezerra e Gonçalves (2007) ao pesquisarem as percepções de professores de uma escola pública em Santo Antão/ PE, identificaram que as noções agrupadas na tendência antropocêntrica, retratam o ambiente como um lugar ou espaço para que o ser humano viva, ou seja, o ambiente é um recurso, um meio, voltado a atender as necessidades do ser humano.

A maioria dos participantes se coloca à margem da natureza e carrega a visão paradigmática desta sociedade moderna. De acordo com estas concepções, o ambiente está a serviço do ser humano, tendo o homem prioridade para usufruir de todos os seus benefícios não considerando os demais seres vivos, exercendo uma postura dominadora sobre os 
mesmos. A crença de dominação, privatização e redução do homem frente ao mundo em que vive, cega a sua visão e o coloca como Senhor, o dono do espaço. Desse modo, não se permite enxergar as relações de interdependência das partes com as partes e com o todo (GUIMARÃES, 2018).

A partir das análises, inferimos que o ambiente é traduzido pelos sujeitos como um espaço social de relações. Desse modo, para os participantes deste estudo, a representação de ambiente está fundamentada em suas experiências no ambiente social, considerando-o como ponto de partida para reflexões.

O ambiente ainda é visto de forma fragmentada, onde sua plenitude não é contemplada pela consciência humana (MELLO-SILVA e GUIMARÃES, 2018). No entanto, os problemas ambientais nascem da relação de coisificação da natureza pelo homem, o que tem provocado o desequilíbrio do ecossistema e consequente adoecimento planetário que vem acometendo a saúde de todos (MELLO-SILVA e GUIMARÃES, 2018).

Saúde e ambiente são indissociáveis e interdependentes (BRASIL, 2002). Embora a concepção sobre "o que é saúde" venha sendo propagada no discurso social ao longo de décadas, o pensamento reducionista ainda permeia as ações nesta era. Neste contexto, ainda que o conceito de saúde vigente se proponha ampliado, contempla apenas a saúde humana. Entendemos que a saúde é complexa e corresponde a uma unidade planetária.

$\mathrm{O}$ artigo $3^{\circ}$ da lei 8080/90, considera o meio ambiente como um fator determinante e condicionante da saúde. Dessa forma exerce influência sobre o processo de saúde-doença (BRASIL,1988). Neste contexto, cerca de 97\% dos participantes deste estudo também compartilham do mesmo pensamento.

O ambiente escolar ganhou notoriedade, sendo delineado através dos apontamentos dos docentes ao longo do questionário. A Ambiência é evidenciada por influenciar no processo saúde-doença, contribuindo com o desencadeamento ou agravamento de transtornos psicológicos como estresse, depressão, ansiedade.

Para Paula (2018) um ambiente escolar desfavorável consiste em um fator de desgaste ao docente, comprometendo a saúde do professor. A ambiência consiste na articulação entre o ambiente físico e psicossocial e implicam diretamente na manutenção do bem-estar biopsicossocial dos indivíduos. Com relação ao ambiente físico, o ruído e a temperatura, 
configuram-se como os principais fatores ambientais físicos, ressaltados pelos docentes como risco à saúde.

Segundo Batista et al., (2010) o desconforto térmico é uma das queixas mais comuns da classe docente. Este fato também foi observado no nosso estudo. A escola fica localizada no distrito de Xerém, uma região de temperatura amena, devido a proximidade com a serra dos órgãos. No entanto, acreditamos que esse calor excessivo, sobretudo no verão, está relacionado ao fenômeno mudanças climáticas, ou seja, a um fator ambiental. Segundo MelloSilva e Guimarães, (2018) as mudanças climáticas provocam ondas de calor e frio, conferindo uma ameaça à saúde humana. Desse modo, podemos perceber o quanto a qualidade de vida humana, mesmo em seus espaços sociais, é dependente da saúde ambiental.

A rouquidão foi relatada pelos professores como um desconforto desencadeado pelo ambiente escolar. A voz do professor é a ferramenta de comunicação verbal fundamental no processo de ensino-aprendizagem. Ambientes ruidosos exigem falas em intensidade mais forte. A repetição deste comportamento, pode gerar desgastes nas estruturas de fonação, prejudicando a saúde vocal do professor (GUIDINI et al., 2012).

Além dos aspectos físicos, o ambiente psicossocial implica diretamente na ambiência escolar. Este dado pode ser traduzido como as relações interpessoais que se desenvolvem no ambiente escolar, sobretudo a relação professor- aluno.

As demandas da docência expõem os professores a processos de desgastes psicofísicos. Isto pode culminar em ausências ou até mesmo afastamento temporário das atividades laborativas (GASPARINI, BARRETO e ASSUNÇÃO, 2005). Observamos que, os professores que possuem maior tempo de trabalho escolar e de magistério na escola estudada, são os mesmos que já precisaram se ausentar por problemas de saúde ou que apresentam doença ou desconforto relacionados à profissão. Esse achado concorda com os estudos analisados por Souza e Leitte (2011), que associam a maior ocorrências de agravos à saúde mental em professores com maior tempo de serviço.

Dentre os agravos de saúde relacionados às ausências, ressaltamos os de maior relevância como a rouquidão, estresse, depressão, problemas respiratórios e osteomusculares. Quanto ao desenvolvimento de doenças ou desconforto relacionados ao 
exercício da sua profissão na referida instituição, foram relatados com maior relevância o estresse, os distúrbios da voz e problemas osteomusculares.

Observa-se uma similaridade entre os fatores que levaram ao afastamento do professor e os agravos adquiridos no exercício da profissão. Queremos chamar a atenção para a persistência de ocorrência dos casos de estresse, distúrbios da voz e problemas osteomusculares. Consideramos estes fatores relevantes, mesmo não sendo citado por todos os participantes, pois além de acometerem a saúde da comunidade escolar também intervêm no processo de ensino-aprendizagem e estão associados a questões socioambientais.

O estado de saúde do professor sofre influência do ambiente e da ambiência escolar, o que pode conferir um determinante da saúde do professor. Os agravos à saúde física e mental estão associados a fatores ambientais internos (dimensão física escolar) e externos (ambiente planetário).

A escola é um ambiente educativo por natureza, coopera com a construção, preparação do aluno como cidadão para lidar com as questões sociais, por isso justifica-se como espaço propício para educação em saúde e ambiente. A figura do professor é fundamental no que tange a promoção da saúde, visto que o seu papel, enquanto educador, influencia e contribui com a construção de conceitos relacionados à saúde e ao ambiente.

As concepções dos docentes, bem como sua didática, possibilitam o compartilhamento do saber e estimulam o pensar e o agir. Neste estudo, professores das áreas de artes e Ed. física, Biologia História e Geografia relataram o desenvolvimento de atividades educativas com os temas transversais, saúde e ambiente. É válido ressaltar que, em sua maioria, os temas foram trabalhados de forma restrita ao campo disciplinar. Saúde e ambiente estão concatenados, e perpassam por diferentes áreas do saber, sendo assim, restringi-los a uma área específica, seria minimizar sua abrangência e seu potencial. A transversalidade compreende uma proposta interdisciplinar e nesse sentido conferem aos Parâmetros Curriculares Nacionais a possibilidade de trabalho com temas sociais geradores de reflexão. A implementação da transversalidade, introduziu a discussão escolar temas sobre saúde e ambiente. As temáticas devem ser incorporadas ao contexto educativo por meio de uma abordagem interdisciplinar ou transdisciplinar promovendo a articulação de diferentes saberes (MARINHO, SILVA e FERREIRA, 2014). A transdisciplinaridade envolve uma 
abordagem complexa de conhecimento, por sua vez, significa a adoção de uma abordagem holística de conhecimento visando superar a tendência cartesiana fragmentadora do conhecimento ( SANTOS, FUJIKI e COSTA, 2016). Nesse sentido, Basarab Nicolescu afirma que a transdisciplinaridade "se preocupa com o que está entre as disciplinas, através das diferentes disciplinas e além de todas as disciplinas. Seu objetivo é compreender o mundo contemporâneo, no qual um dos imperativos é a unidade do conhecimento" (NICOLESCU, 1999)

Um aspecto nos chama atenção por duas vertentes. Embora a escola esteja situada em uma região cercada pela Mata Atlântica, próximo a serra dos órgãos. Quando os docentes foram indagados no questionário sobre pontos positivos do ambiente escolar, alguns aspectos relevantes ressaltados foram o ambiente escolar arborizado citado por 9,6\% da amostra e o ambiente ao entorno da escola que é cercado por parte da mata atlântica considerado por $16,1 \%$ dos participantes. No entanto, ainda que estes fatores tenham sido elencados por uma pequena parte dos participantes, uma parcela significativa desta amostra desconsidera sua presença e importância, ou seja, a proximidade com a natureza se tornou irrelevante.

Guimarães (2012), afirma que a supervalorização da questão econômica em detrimento da social provocou um distanciamento entre ser humano e natureza. Dessa forma, a natureza se tornou indiferente para o ser humano. Potencializar a saúde, por meio da sinergia entre a comunidade escolar e seu habitat, otimiza as relações humano-humano e humano-ambiental, beneficiando o processo de ensino-aprendizagem.

Em contrapartida, os fatores positivos e negativos ressaltados ao ambiente escolar, apontam para o ambiente interno, mais precisamente para o ambiente psicossocial, o que coloca em evidência o alto grau de representatividade e relevância deste lócus para os sujeitos.

\section{CONSIDERAÇÕES FINAIS}

As concepções e percepções dos docentes quanto a saúde e ambiente estão pautadas em uma visão paradigmática sustentadas por um pensamento simplista, observado em suas falas e práticas. Essas concepções comandam o discurso e a práxis do professor, muitas vezes 
limitando suas possibilidades e criatividade, negligenciando o potencial de suas ações e intenções. Nesse sentido, entendemos que a concepção do indivíduo é a base para construção de qualquer processo analítico e perceptivo, funcionando como ponto de partida para elaboração de ideologias, estilo de vida, atividades e metodologias.

A escola é um coletivo de pessoas, com diferentes perfis sociodemográficos, oriundos de lugares diferentes, com costumes e problemas diferentes. Considerando a complexidade da composição do ambiente escolar, pode-se inferir que a escola é também é um reflexo da sociedade, sendo assim, a ambiência construída pelas relações interpessoais, a própria organização e sobrecarga do trabalho, estrutura e infraestrutura sofrem influências da qualidade de vida que cada indivíduo participa e dos problemas sociais que permeiam a vida dos sujeitos, essa situação de vulnerabilidade deve nos causar inquietação para ação com intervenção para Promoção da Saúde.

Nesse sentido, a escola com seu potencial transformador pode inverter este processo, se reinventando em suas ações, abrindo as portas para uma abordagem complexa, transdisciplinar, partindo de dentro para fora, usando ferramentas da Educação ambiental Crítica para a Promoção da Saúde. Como parte deste processo de transformação, os docentes possuem um papel significativo, suas ações têm o potencial de nortear novas perspectivas e abrir novos horizontes aos seus alunos que, representam grupos sociais diversos. Dessa forma, acreditamos que, melhorando a sua qualidade de vida e saúde dos professores, por meio do trabalho em parceria com os docentes, é possível contribuir para a práxis do cidadão planetário. Sugerimos diversas estratégias pedagógicas como: formação continuada presencial e à distância, oficinas, acompanhamentos pedagógicos e disposição de materiais educativos em plataformas virtuais. É possível despertar e formar alunos/cidadãos comprometidos com a saúde da comunidade escolar, saúde coletiva, logo com a saúde planetária, mas é preciso investir, empoderar e sublimar aquele que pratica a docência.

\section{REFERÊNCIAS}

BARDIN, Laurence. Análise de conteúdo. 4. ed. Lisboa: Edições70, 2010.

BARROS, A. A. Um estudo sobre poluição sonora e cidadania.2014.Universidade de Brasília. Distrito Federal. Dezembro .Disponível em https://bdm.unb.br/bitstream/10483/9713/1/2014_AlzineideAlmeidaBarros.pdf. Acesso em: 07 de Julho de 2020. 
BATISTA, J. B. V; CARLloto, M, S; COUTINHO, S. A; PEREIRA, D. A. M; PEREIRA, D. A. M; AUGUSTO, L.G.S. O Ambiente Que Adoece: Condições Ambientais De Trabalho Do Professor Do Ensino Fundamental. Cad. Saúde Colet, Rio de Janeiro, v.18, n.2, pp. 234-42, 2010. Disponível em: http://www.cadernos.iesc.ufrj.br/cadernos/images/csc/2010_2/artigos/CSCv18n2_234-242.pdf 07 de Julho de 2020.

BATISTA, J.B.V., MOREIRA, A.M., CARLLOTO, M.S. Depressão como Causa de Afastamento do Trabalho: Um Estudo com Professores do Ensino Fundamental. Revista Psicologia.

v. 44, n. 2 , pp. 257-262, abr./jun. 2013. Disponível em : https://dialnet.unirioja.es/servlet/articulo?codigo=5631465. Acesso em 07 de Julho de 2020.

BEZERRA, T. M. O.; GONÇALVES, A. A. C. Concepções de meio ambiente e educação ambiental por professores da Escola Agrotécnica Federal de Vitória de Santo Antão-PE. Biotemas, Florianópolis, v. 20, n. 3, p. 115-125, 2007 Diponível em : .https://periodicos.ufsc.br/index.php/biotemas/article/view/20679/18834. Acesso em: 07 de Julho de 2020.

BOFF, L. Saber Cuidar: ética do humano-compaixão pela Terra, Petrópolis: Vozes, 2017.

BRASIL. Constituição Federal de 1988. Promulgada em 5 de outubro de 1988. Disponível em: http://www.planalto.gov.br/ccivil_03/constituicao/constituição.htm\&gt;. Acesso em: 22 de fevereiro de 2018.

BRASIL. Ministério Da Saúde. Distúrbio de Voz Relacionado ao Trabalho - DVRT. Brasília, DF,2018. Disponível em <http://www.scielo.br/scielo.php?script=sci_arttext\&pid=S1808-

$86942015000200202 \& \operatorname{lng}=e n \& n r m=i s o>$. acesso em 07 de julho de 2020.

BRASIL. Ministério Da Saúde. Organização Pan-Americana Da Saúde. Escolas promotoras de saúde:Experiências no Brasil. Brasília, DF, 2007.Disponível em https://www.nescon.medicina.ufmg.br/biblioteca/registro/referencia/0000002908>. acesso em 07 de julho de 2020.

BRASIL. Ministério da Saúde. Secretaria de Políticas de Saúde. As Cartas da Promoção da Saúde. Brasília, DF, 2002. Disponível em < https://bvsms.saude.gov.br/bvs/publicacoes/cartas_promocao.pdf> acesso em 07 de julho de 2020.

BUSS, P. Promoção da saúde e qualidade de vida. Ciência \& Saúde Coletiva, 5(1):163-177, 2000. Disponível em <http://www.scielo.br/scielo.php?script=sci_arttext\&pid=S1413-

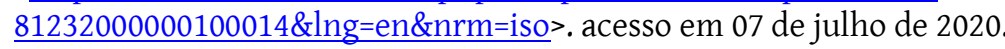

CARDOSO, V; REIS A. P. Dos; IERVOlino, S. A. Escolas Promotoras de Saúde. Rev Bras Crescimento Desenvol Hum. v.18, n.2, p.: 107-115. 2008. Disponível em <http://pepsic.bvsalud.org/pdf/rbcdh/v18n2/01.pdf >. acesso em 07 de julho de 2020.

CZERESNIA, D; FREITAS, C. M. F. Promoção da Saúde. Editora: Fiocruz. 2009

FILLIS, M. M; ANDRADE, S. M. A; GONZÁLEZ, MELANDA, F. N; MESAS, A. E. A Frequência de problemas vocais autorreferidos e fatores ocupacionais associados em professores da educação básica de Londrina, Paraná, Brasil. Cad. Saúde Pública, Rio de Janeiro , v. 32, n. 1, p.1-10. 2016. Diponível em https://www.scielo.br/scielo.php?pid=S0102-311X2016000100701\&script=sci_abstract\&tlng=pt acesso em 07 de julho de 2020.

FREIRE, P. Educação como prática de Liberdade. Rio de Janeiro: Paz e Terra, 1989.

FREIRE,Paulo. Pedagogia do oprimido, 17a. ed. Rio de Janeiro, Paz e Terra,1987 
GASPARINI, S. M; BARRETO, M. S; ASSUNÇÃO, A. A . O professor, as condições de trabalho e os efeitos sobre sua saúde. Educação e Pesquisa, São Paulo, v. 31, n. 2, p. 189-199, maio/ago. 2005. Disponível em <http://www.scielo.br/scielo.php?script=sci_arttext\&pid=S1517- Accesso em 07 Julho 2020.

GIBBS, E. P. J. The Evolution of One Health a decade of progress and challenges for the future.Veterinary Record.v.174, n.4, Janeiro. 2014. Disponível em < http://www.ifiad.ie/wp-content/uploads/2017/11/Historyone-health.pdf> Accesso em 07 Julho 2020.

GUIMARÃES, M. A Formação de Educadores Ambientais. Campinas, SP:Papirus, 2012.

GUIMARÃES, M. A Formação em Geografia e a Questão Ambiental. Revista História, Natureza e Espaço. v. 1. n. 1 (2012). Disponível em < https://www.e-publicacoes.uerj.br/index.php/niesbf/article/view/4361. Acesso em 07 de Julho de 2020

GUIMARÃES, M. Pesquisa e Processos Formativos De Educadores Ambientais Na Radicalidade De Uma Crise Civilizatória Pesquisa em Educação Ambiental, vol.13, n.1, p. 58-66, 2018. Disponível em $<$ http://www.periodicos.rc.biblioteca.unesp.br/index.php/pesquisa/article/view/13483. Acesso em 07 de julho 2020

MARCEZWSKI, M. Avaliação da percepção ambiental em uma população de estudantes do ensino fundamental de uma escola municipal rural: estudo de caso. Dissertação (mestrado em ecologia).Universidade Federal do Rio Grande do Sul. Porto Alegre, p. 187.2006. Disponível em < https://lume.ufrgs.br/handle/10183/8617. Acesso em 07 de julho de 2020.

MARINHO, J. C. B ; SILVA, J. A ; FERREIRA, M. A educação em saúde como proposta transversal: analisando os Parâmetros Curriculares Nacionais e algumas concepções docentes. Hist. cienc. saúde-Manguinhos, Rio de Janeiro , v. 22, n. 2, p. 429-444, June 2015. Disponível em $<$ http://www.scielo.br/scielo.php?script=sci_arttext\&pid=S0104-59702015000200008\&lng=en\&nrm=iso> Acesso em 7 de Julho de 2020.

MELLO SILVA. C.C. Ambiente e Ambiência: Como cuidar?.Disponível em:http://saúde ambiental.blogspot.com/2017/06/ambiente-e-ambiencia-como-cuidar.html. Acesso em: 22 de fevereiro de 2018.

MINAYO, M.C. S; HARTZ, Z. M. A; BUSS, P. M.2. Qualidade de vida e saúde: um debate necessário. Ciência \& Saúde Coletiva, 5(1):7-18, 2000. Disponível em <https://www.scielosp.org/article/csc/2000.v5n1/718/pt/\#ModalArticles. Acesso em 07 de Julho de 2020.

MORIN, E. A cabeça bem feita: repensar a reforma, reformar o pensamento. 9. ed. Rio de Janeiro: Bertrand Brasil, 2004.

MORIN, E. Da ciência a consciência. Rio de Janeiro: Bertrand Brasil, 1997.

MORIN, E. Os sete saberes necessários à educação do futuro. Tradução de Catarina Eleonora F. da Silva e Jeanne Sawaya. São Paulo: Cortez; Brasília, DF: Unesco, 2000.

ORGANIZAÇÃ̃o MUNDIAL DA SAÚDE. Constituição da Organização Mundial da Saúde.Genebra,1946. Disponível em <http://www.direitoshumanos.usp.br/index.php/OMS-Organiza\%C3\%A7\%C3\%A3o-Mundial-daSa\%C3\%Bade/constituição-daorganizacao-mundial-da-saude-omswho.html. Acesso em:20 de março de 2019.

PAULA, L. H . A Influência Da Depressão Dos Docentes Em Sua Prática Pedagógica No Ensino Fundamental De Duas Escolas Municipais Da Cidade De Santos - São Paulo - Brasil. 2018-116 p. Dissertação (Mestrado em Ciências da Educação) Universidad Autónoma de Asunción. Paraguay. 2018.

PEREIRA, E. F; TEIXEIRA, C. S. T; PELEGRINI, A. MEYER, C; ANDRADE, A .D; LOPES, A. S. Ciencia e Trabajo. Estresse Relacionado ao Trabalho em Professores de Educação Básica, Santiago, v. 16, n. 51, p. 206-210, dic. 2014. Disponível em <https://scielo.conicyt.cl/scielo.php?script=sci_arttext\&pid=S071824492014000300013\&lng=es\&nrm=iso> Acesso em 07 de Julho de 2020. 
Promoção da saúde única: concepções e percepções sobre ambiente e saúde de professores de uma escola pública em Xerém

PROVENZANO, L. C. F. A; SAMPAIO, T. M. M. Prevalência de disfonia em professores do ensino público estadual afastados de sala de aula. Rev. CEFAC, São Paulo, v. 12, n. 1, p. 97-108, Feb. 2010. Disponível em < https://www.scielo.br/pdf/rcefac/v12n1/a13v12n1.pdf>. Acesso em 07 de Julho 2020.

REIGOTA, M. 1991. O que é educação ambiental. Brasiliense, São Paulo, Brasil, 63pp.

REZENDE, K. S. As Representações Sociais De Professores Sobre Saúde: Um Estudo De Caso Em Escolas Públicas De Belo Horizonte. 2016-110.Dissertação (Mestrado em Ensino em Saúde ) Universidade Federal dos Vales do Jequitinhonha. Minas Gerais, 2016.

SOUZA, A. N. ; LEITE, M. P. Condições de trabalho e suas repercussões na saúde dos professores da educação básica no Brasil. Educ. Soc.,Campinas, v. 32, n. 117, p. 1105-1121, Dec. 2011 . Disponível em $<$ https://www.scielo.br/scielo.php?pid=S0101-73302011000400012\&script=sci_abstract\&tlng=pt. Acesso em: 07 de Julho de 2020

SOUZA, J. F. Pesquisa-Ação Participante: Realidades E Desafios. Tóp. Educ.Recife, v. 15, n.0 112, p. 65-104, 1997. Disponível em< $\quad$ http://www.scielo.br/scielo.php?script=sci_arttext\&pid=S167869712009000100007\&lng=en\&nrm=iso> Acesso em 07 de Julho de 2020.

SCLIAR, M. História do conceito de saúde. Physis, Rio de Janeiro, v. 17, n. 1, p. 29-41, abril de 2007. Disponível em $<$ https://www.scielo.br/pdf/physis/v17n1/v17n1a03.pdf> Acesso em 07 de Julho de 2020.

TOZONI-REIS,M. F. C. A construção coletiva do conhecimento e a pesquisa-ação participativa: compromissos e desafios .Pesquisa em Educação Ambiental, v.2, n.2, p. 89-107, 2007. Disponível em < https://repositorio.unesp.br/handle/11449/108278> Acesso em 07 de Julho de 2020.

TOZONI-REIS, M. F. C. Temas ambientais como “temas geradores”.Educar em Revista, Curitiba,v. 22, n. 27, p. 93-110, 2006. Disponível em<http://repositorio.unicamp.br/handle/REPOSIP/25814> Acesso em 7 de Julho de 2020.

\section{(cc) $\mathrm{Br}$}

Este trabalho está licenciado com uma Licença Creative Commons - Atribuição 4.0 Internacional. 